\title{
Land cover change interacts with drought severity to change fire regimes in Western Amazonia
}

\author{
Víctor H. Gutiérrez-Vélez, ${ }^{1,2,5}$ María Uriarte, ${ }^{3}$ Ruth DeFries, ${ }^{3}$ Miguel Pinedo-Vásquez, ${ }^{1,2}$ Katia Fernandes, ${ }^{4}$ \\ Pietro Ceccato, ${ }^{4}$ Walter Baethgen, ${ }^{4}$ and Christine Padoch ${ }^{2}$ \\ ${ }^{1}$ Earth Institute Center for Environmental Sustainability (EICES), Columbia University, 1200 Amsterdam Avenue, \\ New York, New York 10027 USA \\ ${ }^{2}$ Center for International Forestry Research (CIFOR), Jalan CIFOR, Situ Gede, Bogor, Barat 16115 Indonesia \\ ${ }^{3}$ Department of Ecology, Evolution and Environmental Biology, Columbia University, 1200 Amsterdam Avenue, \\ New York, New York 10027 USA \\ ${ }^{4}$ International Research Institute for Climate and Society, Columbia University, 61 Route 9W, Palisades, New York 10964 USA
}

\begin{abstract}
Fire is becoming a pervasive driver of environmental change in Amazonia and is expected to intensify, given projected reductions in precipitation and forest cover. Understanding of the influence of post-deforestation land cover change on fires in Amazonia is limited, even though fires in cleared lands constitute a threat for ecosystems, agriculture, and human health. We used MODIS satellite data to map burned areas annually between 2001 and 2010. We then combined these maps with land cover and climate information to understand the influence of land cover change in cleared lands and dry-season severity on fire occurrence and spread in a focus area in the Peruvian Amazon. Fire occurrence, quantified as the probability of burning of individual 232-m spatial resolution MODIS pixels, was modeled as a function of the area of land cover types within each pixel, drought severity, and distance to roads. Fire spread, quantified as the number of pixels burned in $3 \times 3$ pixel windows around each focal burned pixel, was modeled as a function of land cover configuration and area, dryseason severity, and distance to roads. We found that vegetation regrowth and oil palm expansion are significantly correlated with fire occurrence, but that the magnitude and sign of the correlation depend on drought severity, successional stage of regrowing vegetation, and oil palm age. Burning probability increased with the area of nondegraded pastures, fallow, and young oil palm and decreased with larger extents of degraded pastures, secondary forests, and adult oil palm plantations. Drought severity had the strongest influence on fire occurrence, overriding the effectiveness of secondary forests, but not of adult plantations, to reduce fire occurrence in severely dry years. Overall, irregular and scattered land cover patches reduced fire spread but irregular and dispersed fallows and secondary forests increased fire spread during dry years. Results underscore the importance of land cover management for reducing fire proliferation in this landscape. Incentives for promoting natural regeneration and perennial crops in cleared lands might help to reduce fire risk if those areas are protected against burning in early stages of development and during severely dry years.
\end{abstract}

Key words: Amazonia; Bayesian statistical modeling; burn scar mapping; climate change; fire occurrence and spread; INLA; landscape configuration; MODIS; oil palm plantations; remote sensing by satellite; tropical secondary forests; vegetation regrowth.

\section{INTRODUCTION}

Fire is becoming a devastating force in Amazonia and is expected to intensify, given projections in climate and land cover change (Silvestrini et al. 2011). Fires in wet tropical areas have traditionally been associated with slash and burn activities performed by smallholders (Sorrensen 2004, 2009) and, more recently, with largescale agricultural expansion such as soybean and oil palm plantations (Morton et al. 2008, Carlson et al. 2012). Forest conversion to agriculture has been demonstrated to reduce the ability of tropical forest

Manuscript received 12 November 2013; accepted 18 December 2013. Corresponding Editor: B. P. Wilcox.

${ }^{5}$ E-mail: vhg2103@columbia.edu areas such as the Amazon to recycle water, making them drier (Spracklen et al. 2012) and therefore more prone to fire. Recent studies have focused on understanding drivers and impacts of fires in tropical forest areas (Lavorel et al. 2007, Cochrane and Barber 2009). Fires in tropical cleared lands have received less research attention even though they can account for up to $86 \%$ of total fire activity in some areas (Lima et al. 2012) and have multiple deleterious ecological, economic, and social impacts, including damage to crops and farms, degradation of soils and ecosystems, and respiratory illnesses (Shlisky et al. 2009).

Here we develop methods to map fire activity between 2001 and 2010 in cleared lands, using satellite and field data. Then we combine these products with land cover 
and drought severity data to understand the influence of changes in land cover composition and configuration as well as drought severity on fire occurrence and spread. The study takes place in a landscape undergoing rapid land cover and demographic changes, located near the city of Pucallpa in the Peruvian Amazon, where escaped fires from agricultural management have been identified as a growing problem for local communities and ecosystems (Brown et al. 2006, Gobierno Regional de Ucayali 2006).

Fire activity in Amazonia has been almost consistently found to occur predominantly in deforested areas (Aragão et al. 2008, Aragão and Shimabukuro 2010, Lima et al. 2012, Uriarte et al. 2012, Vasconcelos et al. 2013). However, little is known about how land cover changes in deforested lands influence fire activity in the region. Analyzing correlations between temporal changes in forest cover and fire frequency in $0.25^{\circ}$-grid cells in the Brazilian Amazon, Aragão and Shimabukuro (2010) found that fire frequency increased in pixels with slowing deforestation rates. They speculated that this pattern was the result of slash and burn activities in secondary forests and landscape fragmentation. In the Peruvian Amazon, fire occurrence correlated positively with the area of croplands and pastures at the regional scale, whereas at the local scale, in the area of Pucallpa, shrub-dominated land covers were the most fire-prone vegetation types (Uriarte et al. 2012). Negative correlation between the area in fallows and rural population density suggested that higher fire activity is related to a depopulation trend in rural landscapes that reduces the ability of remaining households to control fires.

At the plot level, Uhl and Kauffman (1990) combined field measurements and fire simulations to evaluate fire susceptibility in plots representing a human-induced vegetation sequence in Paragominas (Brazil), from forest to logged forests to pastures and then to secondary forests. Simulations considered differences in fuel availability, microclimate, and rates of fuel moisture loss. They found that flammability was low in old-growth forests, even during prolonged drought, but that logging made forests flammable after 5-6 rainless days within the dry season. Secondary forests were less fire prone than logged forests, becoming flammable after 8-10 days of no rain. Pastures were the most flammable land cover and were susceptible to fire throughout most of the dry season. The work of Uhl and Kauffman (1990) provided important background on the relationship between land cover changes and fire. Yet, empirical evidence of the extent to which land covers representing different stages of development in deforested areas inhibit or promote fire is limited.

The establishment of permanent agriculture can reduce flammability, given the lower fire use in this system compared to slash and burn agriculture and the higher economic value ascribed to these cultivations (Nepstad et al. 2001, Sorrensen 2004, Lavorel et al. 2007, Barlow et al. 2012). Yet, empirical evidence of the relative influence of perennial agriculture on fire occurrence and spread compared to regrowing vegetation is scarce. In the Brazilian Amazon, Aragão and Shimabukuro (2010) found that areas with lower proportions of intensive agriculture had a higher fire incidence than those covered by a similar proportion of total agriculture (both intensive and extensive). However, as the area covered by intensive agriculture increased, fire incidence declined compared to areas with similar proportions of total agriculture, which maintained higher fire incidence. The authors attributed these differences to a lower fire use and a reduction in fuel loads in areas dominated by intensive agriculture.

Drought has been identified as one of the most relevant drivers of fire activity in the Amazon (Aragão et al. 2008, Fernandes et al. 2011, Uriarte et al. 2012, Vasconcelos et al. 2013) and might explain spatial and temporal differences in the contribution of different land covers to fires. For instance, drought severity can double fire risk in areas predominantly covered by agricultural fields in western Amazonia (Uriarte et al. 2012). Yet knowledge is scarce about the extent to which variations in drought modulate the relative influence of land covers representing different stages of vegetation regrowth and perennial agriculture on fire activity.

The specific questions that we address here are as follows. (1) How do land covers representing different stages of regrowth and oil palm development and their configuration in the landscape influence fire occurrence and spread? (2) How does interannual drought variability modify the influence of the different land covers on fire? (3) Can an understanding of the combined effect of land cover change and drought severity on fire help to devise strategies for reducing landscape flammability in the study region?

\section{Methods}

We mapped burned areas annually and combined the maps with annual data from previous studies about land cover (Gutiérrez-Vélez and DeFries 2013) and drought severity (Fernandes et al. 2011) to model fire occurrence and spread in a focus area near the city of Pucallpa (Fig. 1). We now describe the study area, methods developed for burn scar mapping, the other data sets used in the analysis, and the approaches for modeling fire occurrence and spread.

\section{Study area}

The study comprises an area of $2158 \mathrm{~km}^{2}$ around the city of Pucallpa, Peru (Fig. 2). This area has experienced one of the fastest socioeconomic and environmental changes in the Peruvian Amazon. The opening in the 1960s of the highway connecting Pucallpa with Lima, the capital of the country, and the dense road network that emanates from there, triggered a fast process of immigration, agricultural development, and landscape transformation that persists to this day (Uriarte et al. 2012). The area around Pucallpa accounted for $64 \%$ of 


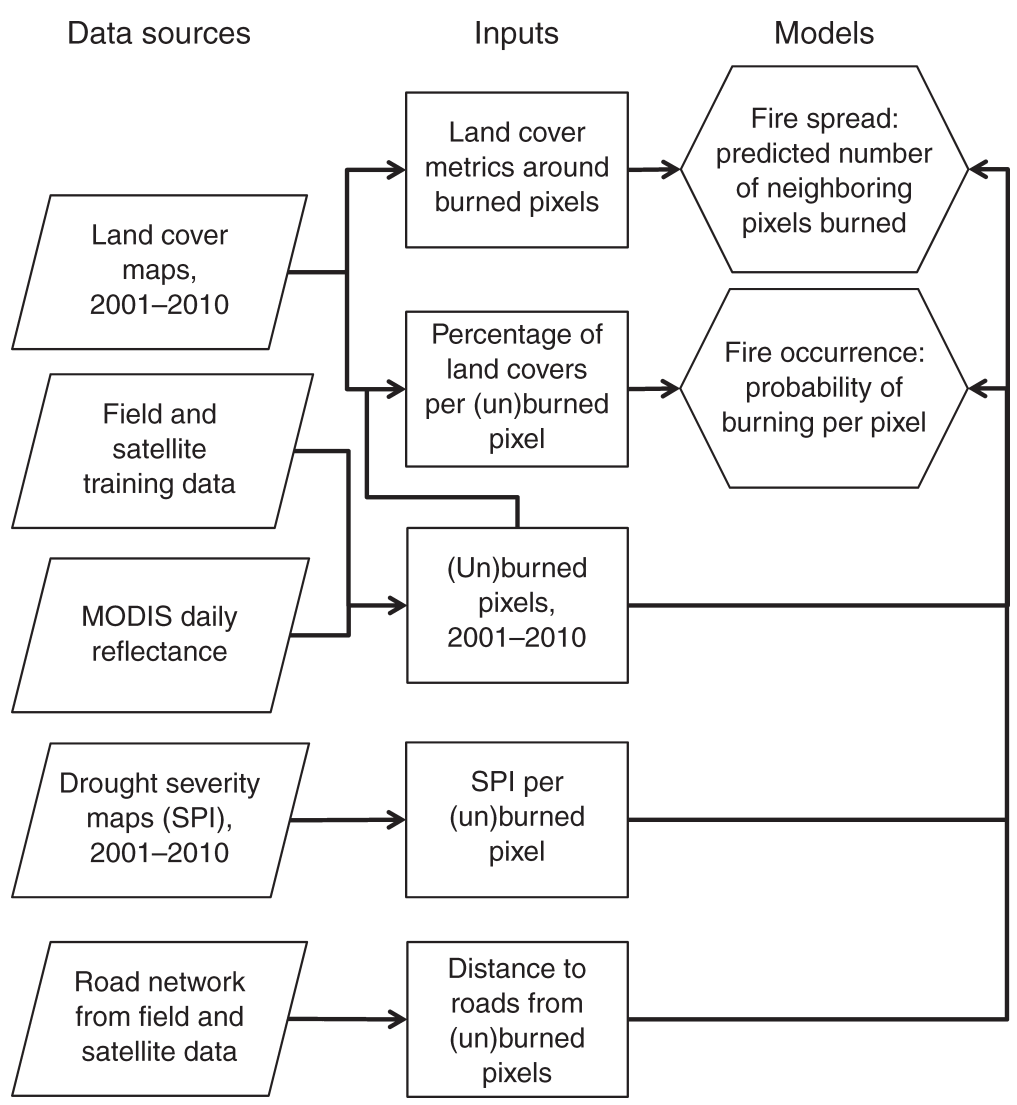

FIG. 1. Flow diagram representing the methods used for modeling fire occurrence and spread in the Peruvian Amazon.

total deforestation and forest degradation in the Peruvian Amazon between 1999 and 2001 (Oliveira et al. 2007). This area has also been subject to the implementation of agricultural development projects. Earlier agricultural expansion was related to rotational crops, the establishment of pastures, and, to a lesser extent, perennial cultivations (Fujisaka and White 1998). In recent years, the study area has experienced a rapid expansion of oil palm plantations. Between 2001 and 2010 alone, $121 \mathrm{~km}^{2}$ of oil palm have been established in the study area, with $91 \%$ occurring during the last half of the decade (Gutiérrez-Vélez and DeFries 2013).

Annual precipitation fluctuates between 1500 and $2500 \mathrm{~mm}$, with a main dry season spanning the months of June through September. Annual mean temperature is $25^{\circ} \mathrm{C}$ and elevation varies between 150 and $250 \mathrm{~m}$ (Barbaran-Garcia 2000, Fujisaka et al. 2000). The relief is mainly composed of non-flooding, undulating plains and knoll hills, with slopes no steeper than $25 \%$ (Gutiérrez-Vélez and DeFries 2013).

\section{Burn scar mapping and characterization}

We mapped burn scars in the study area every year between 2001 and 2010 using daily reflectance data from MODIS bands $1(620-670 \mathrm{~nm})$ and $2(841-876 \mathrm{~nm})$ at 232-m spatial resolution (Table 1). These burn scar maps were used later as the response variable for modeling fire occurrence and spread (Fig. 1). Preprocessing for burn scar mapping consisted of the removal of bad-quality or unreliable pixels using a threestep approach (Appendix A). Classification was based on the calculation of annual and semiannual metrics characterizing temporal changes in reflectance bands 1 and 2 and NDVI (normalized difference vegetation index) in burned areas (Fig. 3a). Metrics consisted of the minimum, maximum, mean, and median values for the prefire and fire seasons (Appendix A). The fire season spans between the months of July and November, when $95 \%$ of the fires occur, on average, every year (Appendix C: Fig. C1). These metrics were incorporated into a decision tree classifier (Hansen et al. 1996) with training field data used for calibration (Fig. 3b; see Appendix A). Selected metrics consisted of prefire median minus fire minimum NDVI values and fire minimYesum NIR (near-infrared radiation) values (Fig. 3b).

Previous studies have demonstrated the suitability of Landsat imagery for mapping burn scars in forested areas (Alencar et al. 2004, 2006, 2011, Morton et al. 2011, Lima et al. 2012). The 30-m spatial resolution of Landsat multispectral data makes this sensor ideal for an accurate detection and quantification of the extent 


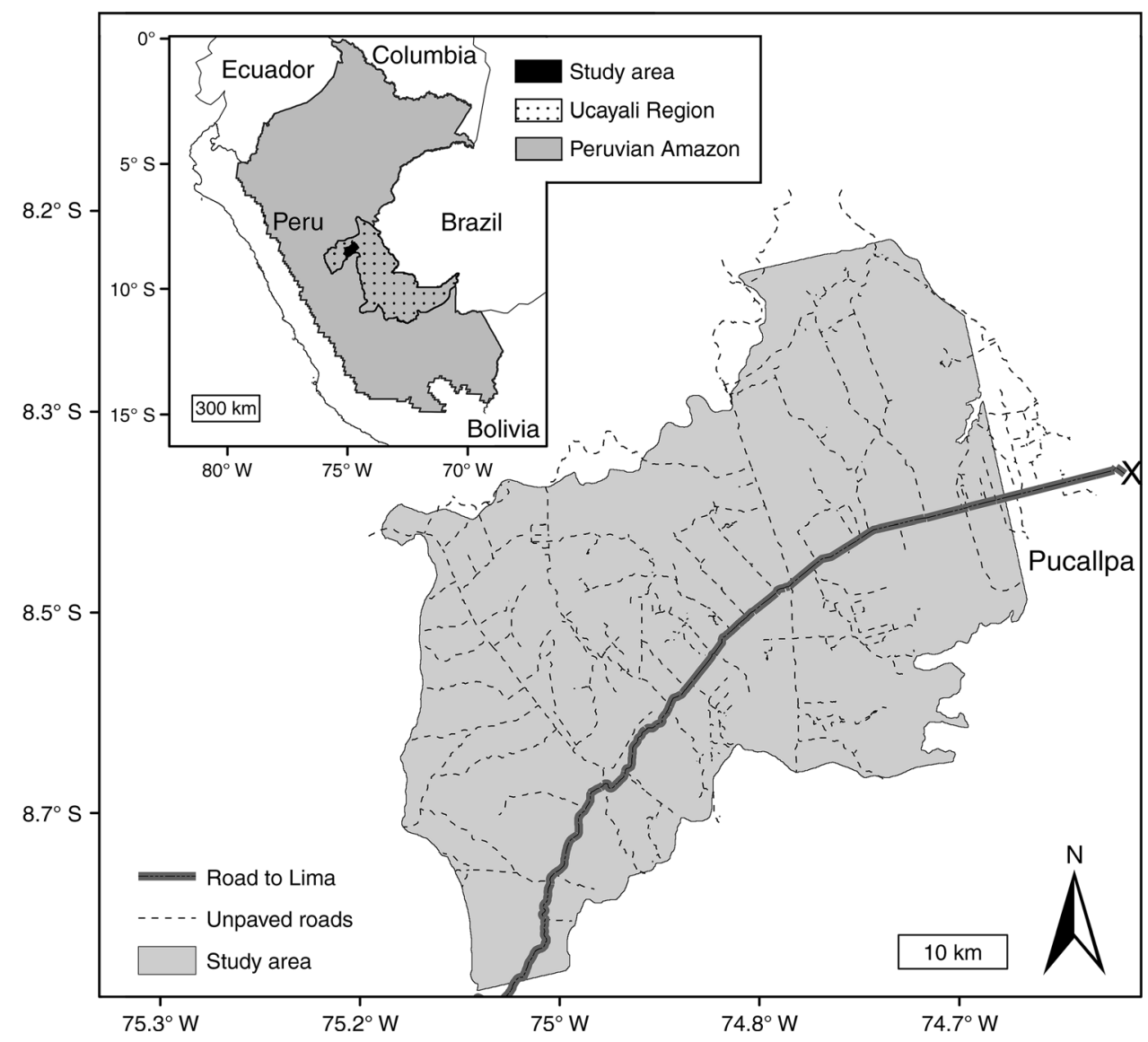

FIG. 2. Study area in the Peruvian Amazon.

affected by burning, including small burned areas. However, the lower temporal resolution of Landsat, combined with high cloud cover in humid tropical regions, makes this sensor less ideal for detecting burn scars, particularly in non-forested lands where the burning signal disappears soon after fire due to a quick vegetation regrowth (Appendix C: Fig. C2). Here we used the daily MODIS reflectance data to increase the ability to detect burn scars that occurred throughout the fire season. We also assessed the minimum burn scar size that can be detected reliably with the method, given the coarser resolution of MODIS data compared to Landsat.

Validation was assessed as the ability of the decision tree calibrated in 2010 to map burn scars in a different year, using 2009 as the reference. Calibration and validation data were obtained from field campaigns during the fire seasons of 2009 and 2010. Calibration and validation data consisted of field measurement of the perimeter of burned areas with a GPS receiver (Appendix B: Table B1). Additional training data were obtained from manual delineation of burned and

TABLE 1. Data sources for the variables used for modeling fire regimes in western Amazonia.

\begin{tabular}{|c|c|c|c|c|c|c|}
\hline Data set/sensor & Format & Years & $\begin{array}{l}\text { Path-row } / \\
\text { tile code }\end{array}$ & $\begin{array}{c}\text { No. } \\
\text { data sets }\end{array}$ & $\begin{array}{l}\text { Native } \\
\text { pixel size }\end{array}$ & Source \\
\hline Surface reflectance (MOD09GQ) & raster & $2000-2011$ & h10 v09 & 3884 & $232 \mathrm{~m}$ & LP-DAAC (2001) \\
\hline Landsat TM & raster & 2009,2010 & $06-066$ & 8 & $30 \mathrm{~m}$ & USGS (2011) \\
\hline Landsat TM & raster & 2009,2010 & $07-066$ & 2 & $30 \mathrm{~m}$ & USGS (2011) \\
\hline Land cover maps & raster & $2001-2010$ & & 10 & $30 \mathrm{~m}$ & $\begin{array}{l}\text { Gutiérrez-Vélez and } \\
\text { DeFries (2013) }\end{array}$ \\
\hline Road network & vector & $2009-2010$ & & 1 & $\dagger$ & field data \\
\hline $\begin{array}{l}\text { Standardized precipitation } \\
\quad \text { index (SPI) }\end{array}$ & raster & $2001-2010$ & & 10 & $0.25^{\circ}$ & Fernandes et al. (2011) \\
\hline
\end{tabular}

$\dagger$ Pixel size is not applicable to this data format. 
unburned areas in Landsat scenes acquired from three dates spread along the fire seasons of 2009 and 2010 (Table 1; see Appendices A and B: Table B1). Burned areas that were measured in the field but also delineated visually were counted once and the data from the visual delineation were preferred. We prioritized the visual delineation to assure the inclusion of the whole area burned, considering that some burnings were still active during the field measurements.

We also used data from the MODIS active fire product (MOD14A1) as a benchmark against which improvements in fire mapping were compared. The purpose of the comparison was to select the most suitable product for implementing the fire models based on accuracy. Comparison was performed in terms of the overall error and the number of events and area detected per size classes by our method vs. the active fire product, using our training data as the reference. An event was deemed as detected if the mapped burned area or the active fire product covered the majority of the validation events collected for 2009.

We compared our results with the active fire product because it was the most reliable alternative data source for our analysis. Other standard fire products such as the MODIS burned area (Roy et al. 2008), the Direct Broadcast Monthly Burned Area Product (Giglio et al. 2009), or the global VGT burnt area product (European Commission 2012) were less suitable because they registered no areas burned in the study area during the period of analysis. The active fire product has been also widely used in previous applications for fire modeling and analysis (Siljander 2009, Dlamini 2010, Le Page et al. 2010, Hawbaker et al. 2013, Vasconcelos et al. 2013).

Additional field data were collected and analyzed in order to discuss some of the modeling results in light of the fire typologies that were likely to be captured in the burn scar maps. Data consisted of field measurements of 13 areas burned for agricultural management and 26 escaped fires in 2009. This information was used to calculate the area of both types of burnings per size classes. We also used data from 732 semi-structured interviews performed in 37 communities between 2010 and 2011 in the study area (Uriarte et al. 2012) to assess the frequency with which rural residents reported different land covers to be affected by escaped fires in their properties.

\section{Other input data}

Land cover.-Land cover classification maps for every year between 2001 and 2010 were obtained from a previous study using remote sensing data from Landsat and ALOS-PALSAR (Gutiérrez-Vélez and DeFries 2013). Land cover maps were used to calculate one of the covariates for the fire occurrence and spread models consisting of the proportion of land covers in burned and unburned pixels every year (Fig. 1). Land cover/use categories consist of water bodies, non-vegetated lands, degraded pastures, pastures, fallow, secondary forests,
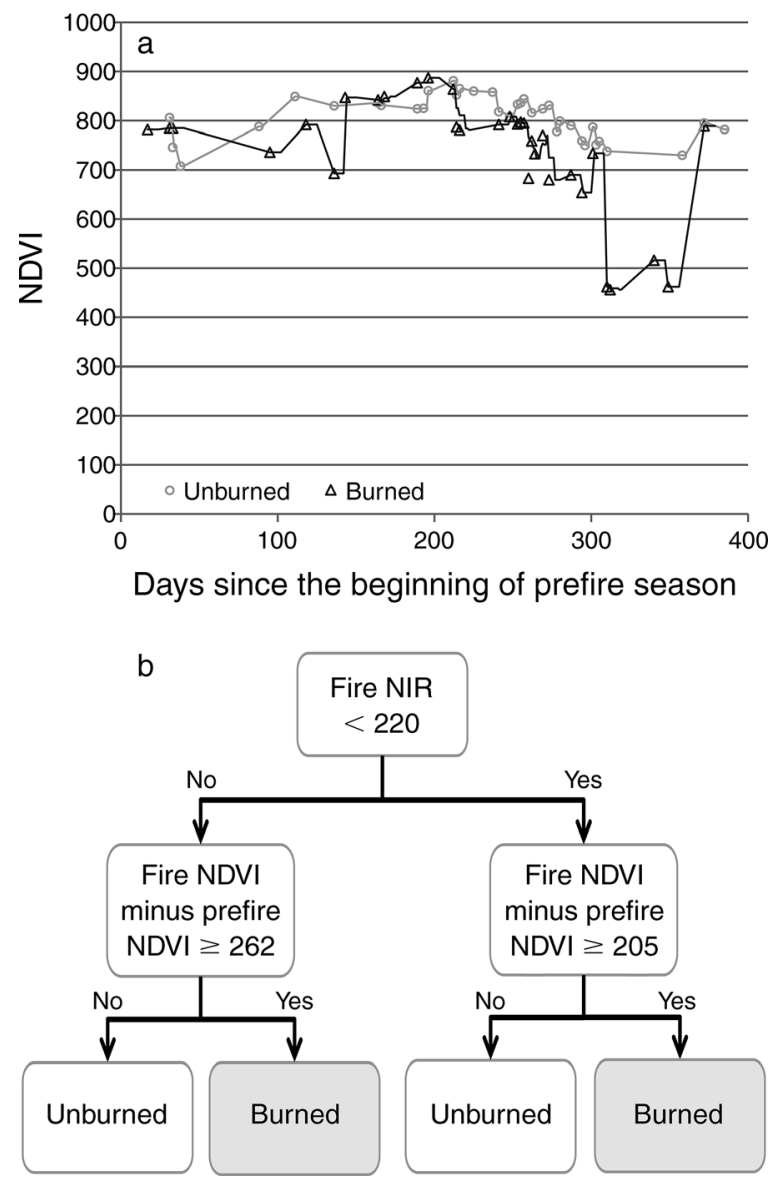

FIG. 3. (a) Typical pattern of temporal changes in NDVI (normalized difference vegetation index) in burned and unburned areas in the study area using daily MODIS reflectance data. This pattern was used as the rationale for developing burn scar classification methods and does not represent average values. Dots indicate the data used after removing unreliable pixels. A moving-average interpolation was added to each time series for visualization purposes. (b) Decision tree used to classify burned and unburned pixels in the study area using fire NIR (near-infrared radiation) and NDVI. Variables are scaled for a range between 0 and 1000.

primary forests, and oil palm plantations. Water bodies comprise lakes and rivers. Non-vegetated lands consist mostly of sand deposits along rivers, built and barren areas, and some recently cleared or burned lands. Degraded pastures are mostly composed of short, scattered grasses intermixed with patches of exposed soil, mainly as the result of overgrazing. This land cover can also include some areas of resprouting herbaceous vegetation after recent burnings. Pastures comprise areas with tall herbaceous vegetation, dominated mostly by brachiaria (Brachiaria sp.), Imperata brasiliensis, and mixed native weed species. Pastures also include some areas of grasses intermixed with small shrubs. Areas of fallow are dominated by bushes and represent early stages of tree succession, with ages of 2-3 years. In contrast, secondary forests typify more advanced stages 
of regrowth, with ages of 3-20 years, approximately. Secondary forests are defined as tree-dominated fields, established in previous cleared lands but with significantly lower stocking than old-growth forests (Gutiérrez-Vélez et al. 2011). Old-growth forests are either areas where the original tree vegetation has never been clearcut but might have been selectively logged, or previously cleared lands that have reached a forest structure resembling unconverted forests.

Land cover maps representing non-oil-palm categories were developed annually using data from the satellite sensors Landsat $\mathrm{TM} / \mathrm{ETM}+$ with an overall accuracy of $93 \%$ (Gutiérrez-Vélez and DeFries 2013). Annual oil palm expansion was mapped based on the classification of oil palm plantations by ages and other land covers in 2010, using data from the satellite sensors Landsat TM and ALOS-PALSAR. Overall accuracy in the classification of oil palm plantations in 2010 was $94 \%$ and the age of oil palm plantations was predicted with an $r^{2}$ of $89 \%$ and a root mean square error of \pm 1.3 (Gutiérrez-Vélez and DeFries 2013). The final resolution of land cover maps was $30 \mathrm{~m}$ (Table 1).

Oil palm plantations every year were further reclassified here in three age categories as young (1-5 years), adolescent ( $6-10$ years), and adult ( $>10$ years). These categories typify different stages of development in terms of canopy closure, ground cover, and fruit production that could be related to fire activity (Gerritsma and Soebagyo 1999, Bruinsma 2009, Gutiérrez-Vélez et al. 2013). Young plantations are characterized by an open canopy and are commonly associated with herbaceous ground cover including kudzu (Pueraria phaseoloides) and the grass Imperata brasiliensis. Harvesting is absent or marginal in young plantations. Adolescent plantations constitute intermediate stages of canopy closure and weed suppression, as well as the beginning of fruit production. Adult plantations represent a full canopy closure that suppresses most ground cover, and include the peak of fruit production. The land cover maps do not include degraded adult oil palm plantations because their spectral signature was not distinguishable from other land cover classes (Gutiérrez-Vélez and DeFries 2013).

Distance to roads.-The road layer used for the analysis was developed from a detailed tracking of the road network during the field campaigns of 2009 and 2010 with a handheld GPS, and complemented with visual interpretation of Landsat images for 2010 (Table 1). Distance to roads from every burned and unburned pixel was used as a covariate for the fire occurrence and spread models (Fig. 1). Data include the main road connecting the city of Pucallpa to Lima and unpaved secondary roads (Fig. 2).

Dry-season severity.-Dry-season severity was quantified using the standardized precipitation index (SPI) (McKee et al. 1993). The SPI is the number of standard deviations that the observed cumulative precipitation during any given period of interest deviates from the climatological average. SPI values were assigned to each burned and unburned pixel every year and then were used as a covariate for the fire occurrence and spread models (Fig. 1). We used the SPI during the months of July, August, and September (JAS) because it is closely correlated with fire activity in the study area (Fernandes et al. 2011, Uriarte et al. 2012). Accurate calculation of SPI requires a long-term time series of precipitation data. SPI was therefore calculated by interpolating precipitation data from rain gauge stations in Peru (made available by the Servicio Nacional de Meteorologia y Hidrologia [SENAMHI]) for the period 19702010 at $0.25^{\circ}$ resolution using the Cressman (1959) method (Table 1).

\section{Statistical modeling}

Description of the models.-We developed conditional autoregressive (CAR) models to evaluate two processes associated with fire activity in the study area, namely fire occurrence and spread (Fig. 1, Table 2). Fire occurrence was defined as the probability of burning for each 232-m spatial resolution MODIS pixel included in the burn scar maps as a function of the proportion of different land covers within the pixel, their distance to roads, and the corresponding SPI each year (Fig. 1). Fire spread was defined as the prediction of the number of pixels burned in the vicinity of each burned pixel as a function of the area of each land cover and their configuration (McGarigal and Marks 1995), distance to roads from the central pixel, and SPI of the central pixel.

We built two separate models to predict fire spread in a $3 \times 3$ pixel window around each burned pixel as a function of (a) the configuration or (b) the area of each land cover within the $3 \times 3$ window. We selected a $3 \times 3$ pixel window because larger windows would include some land cover patches that influence burnings other than the one fire associated with the central pixel, introducing noise to the models.

We selected the landscape shape index (LSI) to measure configuration of each land cover inside the 3 $\times 3$ pixel window out of 37 standard class metrics widely used in the landscape ecology literature (McGarigal and Marks 1995). LSI is defined as the ratio between the total edge of all patches in each class and the edge of a hypothetical square with the same area of all patches. Low LSI values indicate more aggregated and regularly shaped patches in a class, whereas large values indicate more irregular and disaggregated patches (Appendix C: Fig. C3). The LSI was selected among the other landscape metrics following the rationale described by Ruiz-Mirazo et al. (2012). First, we calculated all metrics for each land cover (266 variables in total) in the $3 \times 3$ window. Then we ranked the 10 most important metrics per land cover predicting fire occurrence based on a variable importance analysis obtained from a random forest classification (Breiman 2001, Liaw and Wiener 2002). Finally, we extracted the six most important metrics that were common among all land covers 
TABLE 2. Specification used for modeling fire occurrence and spread.

\begin{tabular}{|c|c|c|}
\hline Model settings & Fire occurrence & Fire spread in a $3 \times 3$ pixel window \\
\hline Response variable & probability of burning per MODIS pixel & $\begin{array}{l}\text { predicted number of neighbors burned around } \\
\text { burned pixels }\end{array}$ \\
\hline Response type & binary & count \\
\hline Possible response values & 0,1 & 1 to 9 (total number of pixels in the window) \\
\hline Covariates & $\begin{array}{l}\text { percentage of land covers inside MODIS } \\
\text { pixels, distance to roads, SPI }\end{array}$ & $\begin{array}{l}\text { landscape shape index or area of land covers } \\
\text { around burned pixels, distance to roads, SPI }\end{array}$ \\
\hline Covariate type & continuous, standardized & continuous, standardized \\
\hline Likelihood model & binomial & Poisson \\
\hline $\begin{array}{l}\text { Unstructured and structured } \\
\text { random variable }\end{array}$ & pixel ID & pixel ID \\
\hline Unstructured latent model & random walk of order 2 & random walk of order 2 \\
\hline Unstructured prior & $\log ($ gamma $)$ & $\log ($ gamma $)$ \\
\hline Structured latent model & Besag et al. (1991) & Besag et al. (1991) \\
\hline Structured prior & $\log ($ gamma $)$ & $\log ($ gamma $)$ \\
\hline
\end{tabular}

(Appendix B: Table B2). We selected the LSI because a pairwise correlation comparison showed that it was highly correlated with most other preselected metrics except for the perimeter to area (PA) ratio (Appendix C: Fig. C4). We chose the LSI over the PA ratio because, in contrast to the latter, it does not change with the extent of the landscape or the size of the patches (McGarigal and Marks 1995). LSI is also advantageous over other metrics because it constitutes an intuitive measure of the level of aggregation or compactness of different patches (Appendix C: Fig. C3).

Fire occurrence and spread were modeled under a Bayesian hierarchical framework using the integrated nested Laplace approximation, INLA (Rue et al. 2009). INLA is a novel statistical inference method for latent Gaussian Markov random field models, GMRF (Martino and Rue 2010). INLA constitutes a fast and robust alternative to standard methods for GMRF models such as Markov chain Monte Carlo, making it more suitable for fitting spatiotemporal models involving large data sets such as the one used in this analysis. Fire occurrence was modeled assuming a binomial distribution of the response, whereas fire spread was modeled assuming a Poisson distribution (Table 2).

Covariates were standardized by centering the data around zero and dividing by twice the standard deviation in order to facilitate comparison between estimated parameters (Gelman and Hill 2007). To avoid collinearity between predictors, we identified variables with $|r| \geq 0.40$. Area in forests was highly correlated with area of fallow and pastures. Although area of forests had the highest absolute correlation with fire occurrence among all land covers (Appendix B: Table B3), we discarded this land cover because our main purpose was to understand the influence of postdeforestation land covers on fire occurrence and spread. In the fire spread model, we also found high collinearity between the area of pastures and secondary forests (Appendix B: Table B4). Therefore, we fitted two models excluding either pastures or secondary forests and selected the one that performed the best, based on the predictive measures that we will describe in detail. We also used predictive measures to evaluate whether the inclusion of roads as a covariate, both alone and interacting with SPI, improved the performance of each model.

The models included interactions between SPI and other covariates because our exploratory analyses indicated that the response of fire to some variables was different in wet and dry years (Appendix C: Fig. C5). Interactions between climate and young and adolescent oil palm plantations were excluded because of the low extent of these land covers in early years of the analysis. Most of the oil palm expansion has occurred since 2006, when $91 \%$ of the new plantations were established (Gutiérrez-Vélez and DeFries 2013). Because most data on area of young and adolescent plantations do not cover the full range of SPI values, including the wettest and driest years (2002 and 2005, respectively), these land covers were considered not suitable to assess reliably the effect of their interactions with drought severity. Pixel identity was included as a random effect in the model. To account for spatial autocorrelation, we conditioned the predictions to neighboring pixels, assuming a Besag model (Besag et al. 1991). For temporal autocorrelation, we assumed an independent random noise model (Table 2). We selected weak or uninformative priors for the random effects.

Model evaluation.-Predictive measures for model evaluation consisted of the deviance information criterion, DIC (Spiegelhalter et al. 2002), and the logarithmic score (Gneiting and Raftery 2007). DIC is a measure of the overall fit and complexity of a model, whereas the logarithmic score measures their predictive value. Lower DIC values and logarithmic scores indicate a better model. We also calculated the $P$ value of the model parameters to assess the level of significance of the covariates in their correlation with the response variables.

INLA does not contain a prediction function because predictions are part of the model- fitting process. Therefore, for validation, we reran the selected models 


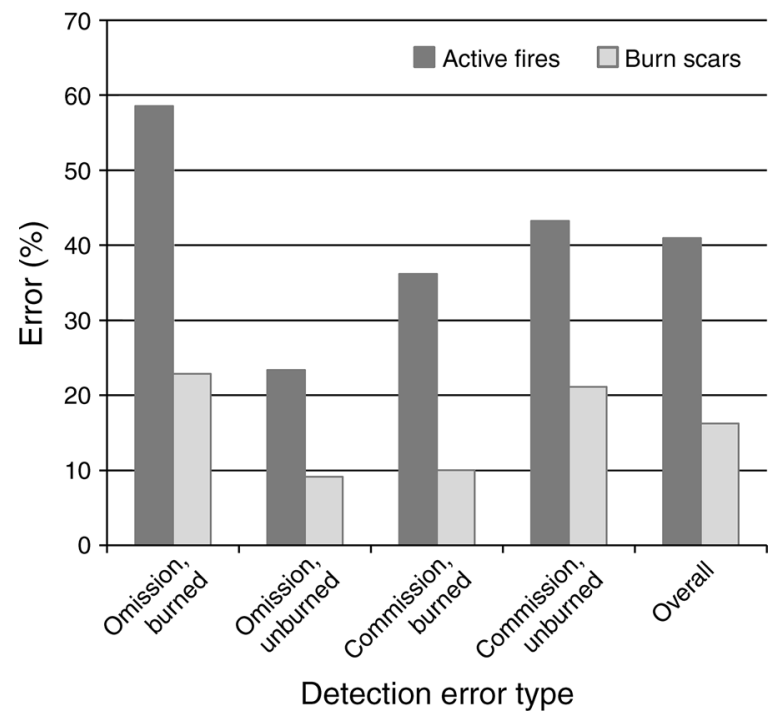

FIG. 4. Omission, commission, and overall errors in the detection of burned areas using the MODIS active fire product vs. the burn scar maps developed here.

leaving out a randomly selected sample representing $10 \%$ of the data. Then we used the predicted values to calculate a coefficient of determination for the crossvalidation data. Cross-validation has been used in other INLA applications (Blangiardo et al. 2013, Cameletti et al. 2013).

Given that SPI values for 2005 deviate considerably from those in other years (Appendix C: Fig. C6), we included an assessment of the extent to which the atypical SPI values in 2005 were influential in the parameter estimates for the fire occurrence and spread models. The evaluation was performed by analyzing the extent to which the exclusion of 2005 from the models changed the significance and sign of the parameters estimated for each covariate. All of the analyses were performed in the $\mathrm{R}$ statistical program, version 2.15.2 ( $\mathrm{R}$ Development Core Team 2013).

\section{Fuel load and types}

Field data also included the measurement of the amount of fuels per fuel types in land covers representing different stages of regrowth (Appendix B: Table B6) Fuel types considered were standing trees, dead fuels, and live fuels in nonwoody vegetation. This information was used to discuss the potential influence of fuel characteristics on some of the modeling results. The amount of fuels in standing trees was quantified in three concentric circular plots (Appendix C: Fig. C7). We used 400 - or $500-\mathrm{m}^{2}$ plots to measure trees with a diameter at breast height (dbh) larger than $10 \mathrm{~cm} ; 100$ $\mathrm{m}^{2}$ plots for trees between 2.5 and $10 \mathrm{~cm} \mathrm{dbh}$; and $30-\mathrm{m}^{2}$ plots for trees between 1.5 and $2 \mathrm{~cm}$ dbh. Values for $\mathrm{dbh}$ were converted to tree biomass using the equation from Sierra et al. (2007). Dead fuels and live fuels in nonwoody vegetation from degraded pastures, pastures, and fallows were collected separately in three square plots of $0.25 \mathrm{~m}^{2}$ located at the edge of the largest plot with an angle of $0^{\circ}, 120^{\circ}$, and $240^{\circ}$ from the plot center with respect to the North (Appendix C: Fig. C7). Dry mass was calculated based on oven-dried samples until constant temperature at $60^{\circ} \mathrm{C}$ for nonwoody materials and $102^{\circ} \mathrm{C}$ for woody materials. Dead fuels and live fuels in nonwoody vegetation for secondary forests were estimated as $16 \%$ and $2 \%$ of aboveground tree biomass, respectively, based on Sierra et al. (2007).

\section{Results}

\section{Burn scar mapping and characterization}

The annual burn scar maps resulted in an overall error of $16 \%$. This error was 2.6 times smaller than the one obtained using the MODIS active fire product (Fig. 4). Total area and number of burning events detected by size classes using our validation data were consistently higher than the results from the active fires product (Appendix C: Fig. C8). The product was suitable for mapping burn scars larger than 10 ha, with $84 \%$ of the area and $89 \%$ of the events larger than 10 ha detected.

Of the burn scars mapped here, $96 \%$ were larger than 20 ha (Appendix C: Fig. C9). Most burned areas for agricultural management measured in the field in 2009 were smaller than 2 ha $(61 \%)$, whereas most $(72 \%)$ of the escaped fires were larger than 10 ha (Appendix C: Fig. C10).

Pasture was the land cover most frequently cited as being affected by escaped fires in our interviews (Appendix C: Fig. C11). The number of respondents reporting fire damage to this land cover was 2.3 times larger than the next most cited land cover, corresponding to regrowing forests.

\section{Fire occurrence model}

SPI was the most important variable predicting fire occurrence, increasing the probability of burning during drier years (Fig. 5a). Area of secondary forests was the land cover variable with the strongest negative correlation with fire occurrence, whereas area of pastures, fallow, and young oil palm plantations was positively correlated. The correlation between oil palm crops by age classes and fire occurrence followed a negative trend: Young plantations were positively correlated, adolescent plantations had a nonsignificant correlation, and adult plantations exhibited a negative correlation (Fig. 5a; Appendix B: Table B7). The selected model did not include roads because their inclusion did not improve model performance (Table 3).

Interactions between SPI and land cover area resulted in a significant negative correlation with fire, except for adult oil palm plantations, which exhibited a nonsignificant correlation (Fig. 5a; Appendix B: Table B7). Negative correlations in the interaction terms mean that more intense dry seasons increase the probability of burning, and that the effect of drought intensifies with a larger area of land cover representing different stages of 
vegetation regrowth. These interactions followed a negative trend. Degraded pastures had the lowest negative correlation with fire occurrence, followed by pastures and fallows, whereas secondary forests represented the strongest negative correlation (Fig. 5a). Because negative SPI values represent drier years, this trend shows that during drier years, fire occurrence is more likely as the area of land covers representing more advanced stages of regrowth increases. For the random subsample used for cross-validation, $R^{2}$ was $22 \%$.

The exclusion of data from the year representing extreme SPI values (2005) did not change the sign or significance of the variables (Fig. 6a). Not surprisingly, SPI was the variable that had the biggest reduction in the parameter estimate but still had the strongest relationship with fire occurrence among all covariates.

\section{Fire spread models}

Land cover configuration.--SPI was the variable most strongly correlated with fire spread (the number of pixels burned in a $3 \times 3$ pixel window around a burn scar), consistent with the results from the fire occurrence model (Fig. 5b). Land covers with irregular and scattered patches (high LSI; see Appendix C: Fig. C3) reduced fire spread for most land covers except for fallow and young plantations, which exhibited a nonsignificant correlation. Interactions between drought severity and LSI resulted in a significant negative correlation with fire spread for fallow and secondary forests, whereas adult oil palm had a weak positive correlation (Fig. 5b; Appendix B: Table B7). These results mean that more disaggregated patches of fallow and secondary forests are associated with more fire spread during dry years, while the relationship is the opposite for adult plantations (Fig. 5b). Interactions between drought and degraded pastures and pastures were nonsignificantly correlated with fire spread. As for fire occurrence, the inclusion of distance to roads as a covariate did not improve model performance (Table 3 ). For the random subsample used for cross-validation, $R^{2}$ was $36 \%$.

The exclusion of data from the year representing extreme SPI values (2005) changed mostly the significance of the parameter estimates for the interactions (Fig. 6b). For short pastures and pastures, the interaction went from nonsignificant to significantly negative and positive respectively. In contrast, for fallows and secondary forests, the interaction went from nonsignificant to significantly negative in both cases. The area of fallow became significantly related to fire spread with a negative correlation. Similarly to the fire occurrence model, SPI was the variable that had the biggest reduction in the parameter estimate, but in this case the magnitude of the relationship was within the range of the other variables.

Land cover area.-The fire spread model excluding the area of secondary forests performed better than the one that excluded the area of pastures (Table 3). SPI was

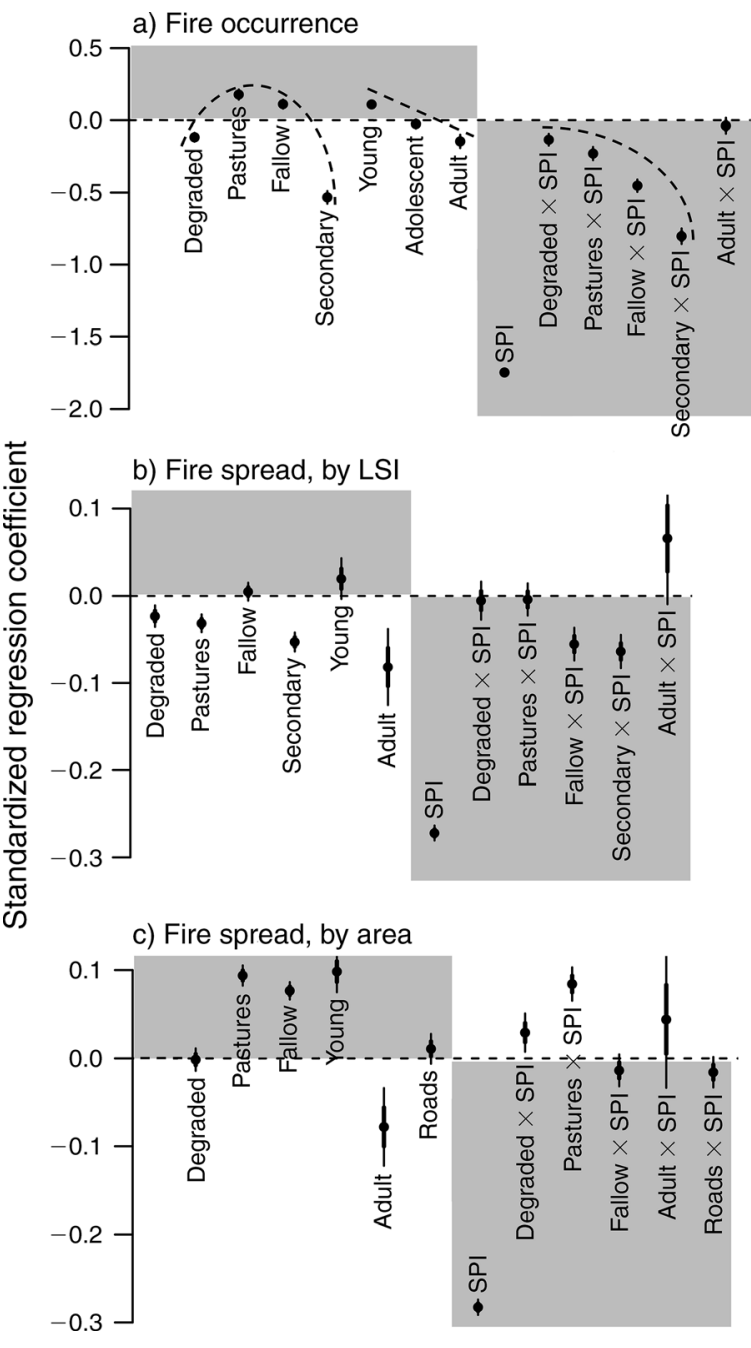

FIG. 5. Standardized regression coefficients for each land cover type, SPI (standardized precipitation index), and interactions with SPI, in relation to (a) fire occurrence and (b, c) fire spread. Fire spread is defined as the number of burned pixels in a $3 \times 3$-pixel window around each burned pixel as a function of the landscape shape index (LSI) in (b), and the area of each land cover within the window in (c). Low LSI values indicate more aggregated and regularly shaped patches in a class; large values indicate more irregular and disaggregated patches (Appendix A: Fig. A3). Thick and thin error bars correspond to $\pm 1 \mathrm{SD}$ and $2 \mathrm{SD}$ around the mean parameter estimate, respectively. Regression coefficients falling inside the shaded areas are correlated with higher fire occurrence (a) or spread (b, c), so negative coefficients for SPI and interactions represent higher fire probability. Dashed lines in (a) suggest trends in the parameter estimates for the relationship between land covers representing different stages of regrowth or oil palm development and fire occurrence. Parameter significance for the covariates measured by the $P$ value is shown in Appendix A: Table A6.

again the variable with the strongest correlation with fire spread in this model. The individual correlation of each land cover area with fire spread resembled mostly the results obtained in the fire occurrence model, with pastures, fallow, and young plantations having a 
TABLE 3. Comparison for all models fitted to predict fire occurrence and spread.

\begin{tabular}{lcr}
\hline \hline \multicolumn{1}{c}{ Model } & DIC & Logarithmic score \\
\hline Fire occurrence with roads & 213604 & 0.24688 \\
Fire occurrence without roads $\dagger$ & 213600 & 0.24688 \\
Fire spread vs. configuration with roads & 187787 & 2.05801 \\
Fire spread vs. configuration without roads $\dagger$ & 187786 & 2.05800 \\
Fire spread vs. area no secondary forest with roads $\dagger$ & 187525 & 2.05592 \\
Fire spread vs. area no secondary forest without roads & 187526 & 2.05591 \\
Fire spread vs. area no pasture with roads & 187613 & 2.05645 \\
Fire spread vs. area no pasture without roads & 187733 & 2.05773 \\
\hline
\end{tabular}

Note: Predictive measures for model evaluation consisted of the Deviance Information Criterion, DIC (a measure of the overall fit and complexity of a model), and the logarithmic score (a measure of the model's predictive value).

$\uparrow$ Selected models.

significant positive correlation and adult plantations a negative correlation (Fig. 5c; Appendix B: Table B7). Degraded pasture was the exception, with a nonsignificant correlation with fire spread. SPI interactions with degraded pastures and pastures were the only land cover-drought synergisms that exhibited a significant correlation with fire spread. The positive sign of both correlations shows that a higher proportion of degraded pastures and pasture within the $3 \times 3$ pixel window was associated with lower fire spread during dry years. For the random subsample used for cross-validation, $R^{2}$ was $37 \%$. Distance to roads had a weak positive correlation with fire spread, but the interaction with SPI resulted in a weak negative correlation.

The exclusion of data from the year representing extreme SPI values (2005) changed the sign of the relationship between the interactive term associated with area of pastures and fire spread, becoming negative (Fig. $6 c$ ). For distance to roads, the interaction went from a nonsignificant to a significantly positive correlation with fire spread. Consistent with the other two models, the parameter associated with SPI had the biggest reduction in the parameter estimate, but as in the case of the fire spread vs. landscape configuration model, the magnitude of the relationship was within the range of the other variables.

\section{Fuel characterization}

The total amount of fuels was the lowest in degraded pastures (Fig. 7a). The total amount of fuels was very similar in pastures and fallows with intermediate values. Secondary forests represented the highest amount of total fuels among land covers representing different stages of regrowth. The amount of biomass in standing trees was highest in secondary forests, negligible in degraded pastures and pastures, and slightly higher in areas of fallows (Fig. 7b). The amount of dead fuels increased monotonically with land covers representing more advanced stages of regrowth (Fig. 7c). The amount of live fuels in nonwoody vegetation was highest in pastures, followed by fallows, while it was lowest in secondary forests, followed by degraded pastures (Fig. 7d).

\section{Discussion}

\section{Burn scar mapping}

Our results demonstrate the advantages of mapping burned area over using standard fire products for local applications. Differences in accuracy between our method and the active fire data set are probably influenced by the different features registered by each data set. The active fire product records only areas that are being burned by the time the satellite passes, whereas our method captures areas that have already burned, independently of the satellite passing time. This difference gives an advantage to our approach that might explain, in part, the higher accuracy. In addition, the resolution of the active fire product is $1 \mathrm{~km}$. A detection with that product means that one or more fires can be occurring in any place within the 1-km pixel; therefore, it has limitations to providing information about the extent or exact location of the burnings. In contrast, the finer spatial resolution $(250 \mathrm{~m})$ of the data used in our method makes it more suitable to assess the location and area of the burnings. The lower performance of the active fire product is supported by evidence from different studies showing that the data set can significantly underestimate the number of fires in Amazonia (Vasconcelos et al. 2013). However, the active fire product is still the most suitable standard product available to use as a benchmark for our study area, given the fact that other standard products described in the Methods section detected no fires during the period of analysis.

Our method proved to be suitable for burn scars larger than 10 ha (Appendix C: Fig. C7). This result constitutes an improvement over previous analogous studies mapping burn scars with MODIS data (Table 4). The performance of our method in the study area, characterized by high cloud cover and persistence, suggests that it has the potential to be implemented elsewhere. In fact, the method proved useful even after retaining only $8 \%$ of the original data after filtering. The application to other areas should consider regional variations in fire seasonality, because our approach relies on radiometric changes during the five month duration of the fire season every year. Burn scar 


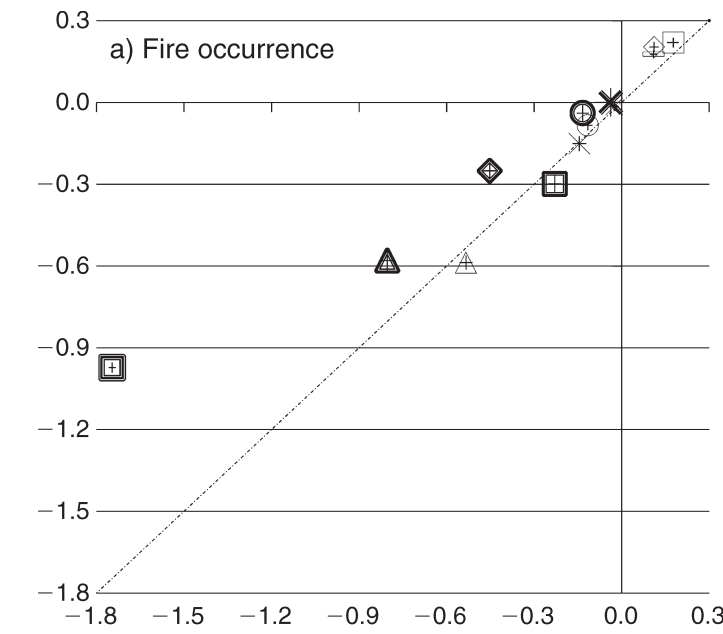

Short

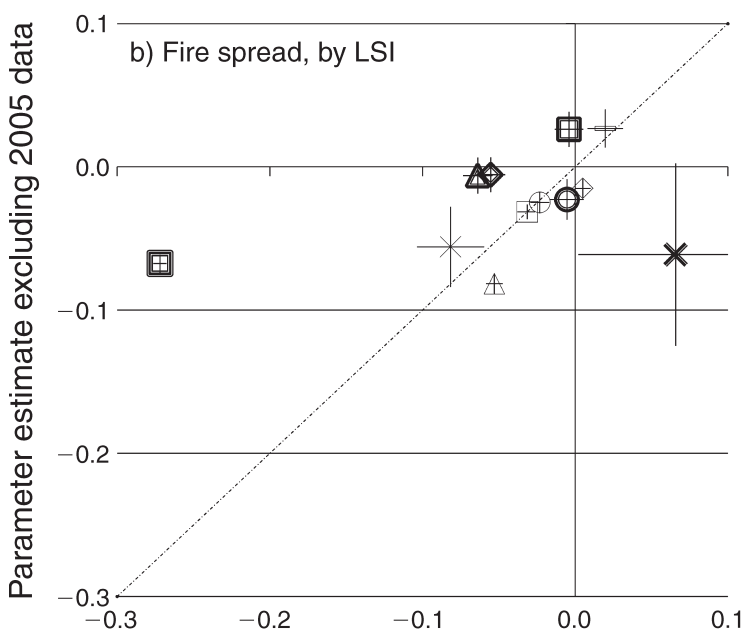

$\square$ Pasture

$\diamond$ Fallow

$\triangle$ Secondary

- Yound palm

* Adolescent palm

$\times$ Adult palm

- Distance to roads

回 SPI

O Short $\times$ SPI

$\square$ Pasture $\times$ SPI

$\checkmark$ Fallow $\times$ SPI

$\Delta$ Secondary $\times$ SPI

$\times$ Adult palm $\times$ SPI

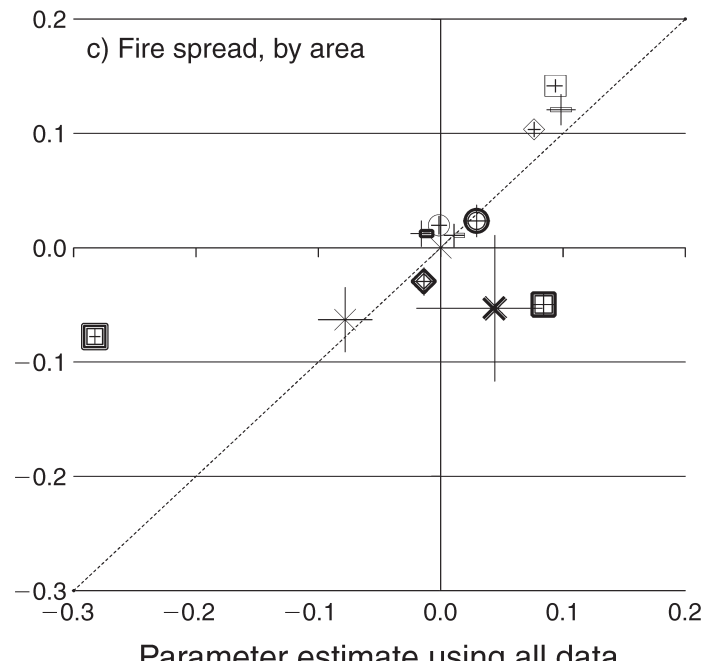

- Distance to roads $\times \mathrm{SPI}$

Parameter estimate using all data

FIG. 6. Changes in parameter estimates (mean $\pm 1 \mathrm{SD}$ ) when excluding data from the driest year (2005) from the analysis for (a) the fire occurrence model, and fire spread models in a $3 \times 3$ pixel window around burned pixels as a function of (b) the landscape shape index, and (c) the area of each land cover. The effect of excluding data from 2005 on the parameter estimates is lower as values are closer to the dashed line. 

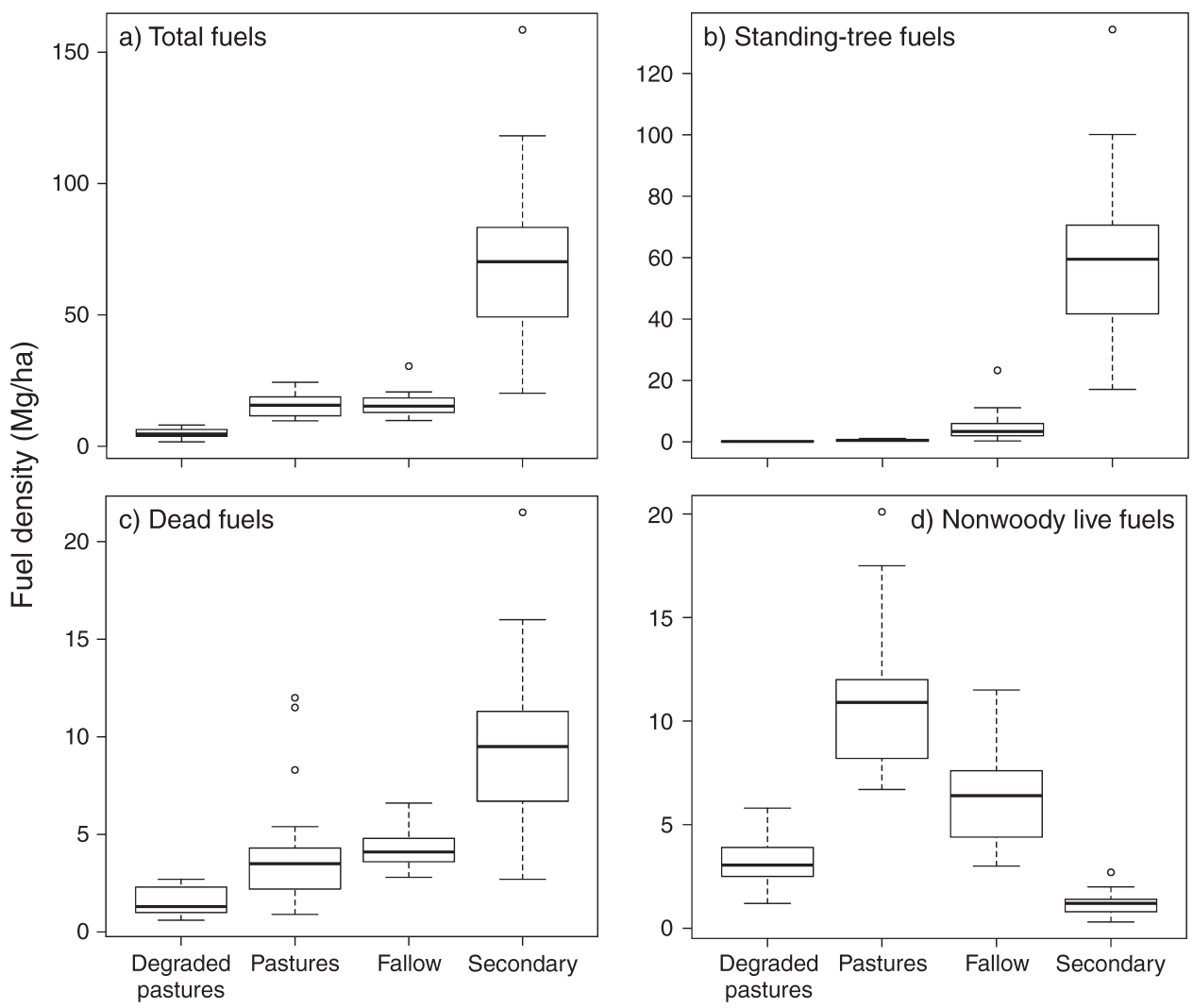

FIG. 7. Amount of aboveground fuels in the land covers representing different stages of regrowth represented as (a) total fuels, (b) fuels in standing trees, (c) dead fuels, and (d) live fuels in nonwoody vegetation. Boxes contain values between the 25 th and 75 th percentiles and thick lines inside them represent the medians. Points outside the boxes represent outliers and whiskers represent the maximum and minimum values excluding outliers. Please note the different $y$-axis scales.

mapping in areas without a marked fire season might require modification to our method.

\section{Fire occurrence}

Our results show that land covers representing different stages of vegetation regrowth have a significant correlation with fire occurrence, but that the sign of the correlation changes with vegetation types (Fig. 5a; Appendix B: Table B7). Potential explanations for these results include (1) burning preferences among residents for different land covers; (2) variations in biophysical conditions of vegetation, including fuel accumulation and types as well as microclimatic conditions; and (3) differences in land management practices or actions in different land covers by rural residents to prevent or control fires.

We will discuss these three potential explanations in light of our empirical evidence and previous literature reports. Assessing the extent to which these or other factors explain the observed patterns requires further data and analysis, as it is likely that no single factor will be sufficient to explain the complex relationship between

TABLE 4. Minimum burn scar area detectable reported by different studies.

\begin{tabular}{|c|c|c|c|c|}
\hline Source & $\begin{array}{l}\text { Minimum } \\
\text { detectable } \\
\text { area (ha) }\end{array}$ & $\begin{array}{l}\text { Dominant } \\
\text { land cover }\end{array}$ & Location & Method \\
\hline This work & 10 & none & Pucallpa, Ucayali, Peru & $\begin{array}{l}\text { decision tree classifier based on temporal } \\
\text { metrics }\end{array}$ \\
\hline Giglio et al. (2007) & 120 & all & World & active fire based algorithm \\
\hline Quintano et al. (2010) & 300 & forest & Galicia & image mining \\
\hline Morton et al. (2011) & 50 & forest & Mato Grosso & burn damage and recovery algorithm \\
\hline Mohler and Goodin (2012) & 200 & tall grass & Flinthills, Kansas, USA & $\begin{array}{l}\text { supervised minimum distance } \\
\text { classification }\end{array}$ \\
\hline
\end{tabular}

Note: Minimum detectable area was defined here as the burn scar size class after which the majority of the events and area burned are detected. Results are shown in Appendix A: Table A6. 
land covers and fire, and their influence might vary with different land covers. Generalization of the possible relationships between land covers and fire should be taken with caution because they can be influenced largely by the socioeconomic and biophysical context in which fire occurs.

Burning preferences by rural residents.-Attributing the results to burning preferences by rural residents for different land covers would imply that the observed burn scars are the result of conversion or management fires instead of fires that escaped to areas where burning was not intended. Although we cannot discard the former completely, our field surveys and measurements suggest that most of the burn scars mapped here correspond to escaped fires. First, the size of the burn scars mapped here is considerably bigger than the typical area burned for land cover conversion and management in the region, which is usually 2 ha or less (Fujisaka and White 1998). This is confirmed by field measurements of the area of both management and escaped fires in 2009 as part of our burn scar mapping. The data showed that from 13 management fires only one $(8 \%)$ was bigger than the minimum size at which our method identifies burn scars reliably (10 ha), whereas 19 out of the 26 escaped fires measured $(76 \%)$ were bigger than 10 ha (Appendix C: Fig. C10). In contrast, $98 \%$ of the burn scars mapped here during the time period were bigger than 10 ha, and $96 \%$ were bigger than 20 ha (Appendix C: Fig. C9). Some burn scars mapped here that correspond to the establishment of large-scale oil palm plantations can be larger than the typical area of smallholder activities. However, most of those plantations were established in forested areas (Gutiérrez-Vélez and DeFries 2013), which were not included in the statistical analysis because of collinearity, as explained previously.

In addition, the significance of each land cover type in the fire occurrence model is in agreement with the frequency with which rural residents report damage of escaped fires to different land covers. Pasture was the land cover with the most significant positive correlation with fire occurrence in our fire occurrence model (Fig. $5 a)$; at the same time, it was by far the land cover most frequently reported by rural residents as being affected by escaped fires in the study area (Appendix C: Fig. C11).

Finally if our results were explained mostly by burning preference, then we would expect that the relationship between land covers and the probability of burning would be less closely associated with drought severity than we observe. The fact that the area in secondary forests reduces the probability of fire occurrence, but that the relationship becomes the opposite when secondary forest interacts with SPI, implies that human preferences for burning, at least in this particular land cover, are not sufficient to explain the relationship between the area of secondary forests and fire.
Differences in biophysical characteristics of vegetation.-Among the land covers representing different stages of vegetation development, degraded pastures and secondary forests had a negative relationship with fire occurrence (Fig. 5a). Our empirical data show that degraded pasture is the land cover with the lowest fuel accumulation of all the categories representing different stages of regrowth (Fig. 7a). Therefore, it is possible that this negative correlation will be influenced to some extent by fuel scarcity.

The area of secondary forests was also negatively correlated with fire occurrence even though our empirical data show that this land cover represents the highest fuel load among all land covers (Fig. 7a). In contrast, pastures and fallows had the highest positive correlation with fire occurrence, with intermediate fuel loads. We rely on our empirical data and previous results by Uhl and Kauffman (1990) to hypothesize that this apparent discrepancy can be explained to some extent by differences in the amount of live fuels in nonwoody vegetation of different land covers. Uhl and Kauffmann found in Paragominas (Brazilian Amazon) that secondary forests became flammable after 8-10 days of no rain during the dry season. In contrast, pastures were flammable throughout most of the dry season. These differences were attributed to a higher availability of rapidly drying fine fuels in pastures. These results are in line with our empirical data showing that the amount of live fuels in nonwoody vegetation is highest in pasture, followed by fallows, and secondary forest represents the lowest values (Fig. 7d). This pattern resembles approximately the relative magnitude of the parameter estimates in our fire occurrence model (Fig. 5a).

In their study, Uhl and Kauffman (1990) found that secondary forests had a higher relative humidity than pastures, particularly during the dry season. Our study did not include site-specific information to validate whether the differences in relative humidity found in Paragominas can be extrapolated to our study area. Future studies could evaluate whether differences in relative humidity explain to some extent the relationships between land covers and fire, particularly considering differences in precipitation regimes (Appendix C: Fig. C12). Future work should also assess the extent to which differences in fuel loads and changes in relative humidity in different land covers as a consequence of drought severity could explain the negative trend in the relationship between fire occurrence and land covers representing different stages of regrowth when they interact with SPI (Fig. 5a). If relative humidity reduces the probability of burning in secondary forests, then it is expected that a combination of a higher fuel load (Fig. 7) and drought would reduce relative humidity in this land cover enough to increase fire probability.

Young oil palm cultivations are commonly associated in the study area with highly flammable herbaceous vegetation such as kudzu (Pueraria phaseoloides), brachiaria (Brachiaria sp.), and Imperata brasiliensis 
(Friday et al. 1999, Nepstad et al. 2001, Lojka et al. 2011, Gutiérrez-Vélez and DeFries 2013). Also, herbaceous vegetation is significantly suppressed by shading as the canopy closes in oil palm plantations (Lojka et al. 2011). Canopy closure in plantations with a tree density typical of the region (143-160 trees/ha) begins at around the fifth year and usually levels off at around 9-10 years after establishment (Gerritsma and Soebagyo 1999). Therefore, canopy closure as oil palm plantations grow might suppress highly flammable herbaceous vegetation and therefore contribute to reducing fire risk. Although no data on fuel characteristics in oil palm plantations representing different age classes are available, it is expected that the negative trend in the correlation between oil palm plantations by age classes and fire occurrence (Fig. 5a) will be influenced by the suppression of ground cover over time, as a consequence of canopy closure.

Differences in land management practices, fire prevention, and control actions. - In the study region, adult plantations require permanent fruit harvesting, but management activities in young plantations are more sporadic, usually consisting of weeding and fertilizing about every two months (Bruinsma 2009). At the same time, oil palm plantations involve relatively large investments and periodic revenue from harvesting. Previous literature has suggested that frequent human presence in permanent cultivations allows owners to detect surrounding fires more quickly, and a higher perceived value in this land cover constitutes an incentive to control fires (Nepstad et al. 2001, Sorrensen 2004, Lavorel et al. 2007, Aragão and Shimabukuro 2010, Barlow et al. 2012). Future research could assess whether higher human presence and perceived value might help to explain why adult plantations did not increase fire probability even when interacting with SPI, in contrast to the interactive term associated with secondary forests that increased fire probability with drier SPI values (Fig. 5a).

\section{Fire spread}

Landscape configuration.-In general, land cover complexity, indicated by high LSI values, was negatively correlated with fire spread, except for fallow cover, with a nonsignificant correlation and young oil palm plantations with a weak positive correlation (Fig. 5b; Appendix B: Table B7). These results are in line with previous studies showing that local landscape homogeneity increases fire spread, whereas discontinuities between land covers in heterogeneous landscapes can act as firebreaks (Vega-García and Chuvieco 2006, Viedma et al. 2009, Moreira et al. 2011). In our case, patches of short pastures, secondary forests, and adult oil palm plantations may inhibit fire spread by acting as discontinuities between large blocks of nondegraded pastures and fallow. In contrast, more homogeneous or aggregated fragments of pastures can propagate fire in any direction in the absence of less flammable land covers acting as firebreaks. Configuration of secondary forests and adult plantations had the most negative correlation with fire spread among land covers. Therefore, elongated patches of these land covers seem to be the most effective at reducing fire proliferation among all vegetation types.

Interactions between land covers and LSI and fire spread were significantly negative for fallow and secondary forests, indicating that more irregular patches in these land covers increase fire spread during drier years. In contrast, the weak positive correlation between fire spread and the interaction between adult oil palm and SPI shows that irregular adult plantations reduce fire spread even during dry years. Correlation between fire spread and the interactions between SPI and degraded pastures and pastures was nonsignificant, indicating that the influence of the shape of these land cover types on fire spread is not mediated by drought (Fig. 5b; Appendix B: Table B7).

Land cover area.-Fire spread was positively correlated with the area of fallow, pastures, and young plantations, but the correlation was negative with area of adult plantations (Fig. 5c). These results are consistent with our findings in the fire occurrence model (Fig. 5a). The exception was the positive interaction between pastures and drought severity, meaning that a greater area in pastures was associated with lower fire spread during dry years (Fig. 5c). Furthermore, the interacting term associated with area of pastures became negatively associated with fire when the driest year was eliminated from the analysis (Fig. 6c). This result suggests that the interaction between pastures and drought severity promotes fire when non-extreme droughts are included. An explanation for these results seems elusive. Drier condition would be expected to increase fire spread by pastures, given the high flammability of this land cover. Future research could assess whether the observed patterns are related to the timing at which land covers burn during extreme droughts. If pastures become susceptible to fire early during severe dry seasons, then the reduction in fuels due to early burning could make them work as firebreaks later, when other land covers with higher fuel loads could become flammable. An understanding of this result requires a comprehensive analysis of fire behavior in tropical mosaic landscapes, in particular in the interface between different land covers, as well as changes in fuel and microclimate properties in vegetation types representing different stages of regrowth under different drought conditions.

\section{Distance to roads}

Distance to roads had a nonsignificant correlation with fire occurrence (Fig. 5a). This result contrasts with previous studies identifying distance to roads as one of the main drivers of fire, especially in tropical areas where the main sources of ignition are humans (Silvestrini et al. 2011, Uriarte et al. 2012). Previous studies cited here 
were performed at considerably larger scales, including only distance to main roads. In contrast, the input road data used for this analysis included a highly dense road network composed mostly of unpaved roads (Fig. 2). High road density means that most cleared lands are relatively accessible and therefore there are no important differences in their exposure to ignition sources. Similar results were reported in Portugal by Moreira et al. (2010), who found that distance to roads was less important for explaining fire ignitions than were population density and land cover types.

\section{Implications for land cover management to reduce landscape flammability}

Our results suggest that the promotion of forest regrowth and the establishment of oil palm plantations in deforested areas can be effective at reducing fire occurrence and spread when they develop beyond initial stages of growth (Fig. 5). Drought severity can undermine the ability of secondary forests to reduce fire, but the influence of adult plantations on fire occurrence and spread seems not to be affected significantly by drought conditions. The implementation of early warning systems, along with mechanisms to reduce and control fire, especially in regrowing forests and young oil palm plantations, is essential for settling in place land cover strategies to reduce landscape flammability. Fire prevention programs in other areas have reduced the number of fires, but have increased the percentage of large burnings (Díaz-Delgado et al. 2004). Therefore, secondary forests would need to be monitored during drier years to avoid the incidence of widespread fires.

Future work could assess whether differences in the response of fire to area of secondary forests vs. adult plantations are related to a higher perceived value of oil palm cultivations among owners as well as a higher human presence after plantations reach a productive age. Secondary forests are usually perceived as areas with low economic value, and therefore farmers could be less effective at preventing them from burning when nearby fires are threatening, as has been demonstrated in other areas of the Amazon (Sorrensen 2000). Therefore, strategies to increase the perceived value of secondary forests could enhance the effectiveness of these land covers at reducing landscape flammability, especially during dry years. Such strategies could include the enrichment with fruit or timber trees. This practice is common among native Amazonians (Pinedo-Vasquez et al. 2002, Padoch et al. 2008), but might not be as widespread among the migrant population increasingly arriving to the region. Other incentives could come from the payment for ecosystem services such as carbon sequestration, water regulation, or habitat restoration.

Our results suggest also that in order to reduce landscape flammability, irregular and disaggregated patches should be implemented for most land covers (Fig. 5b). However, intense drought could increase the susceptibility to fire in areas with disaggregated patches of secondary forests and fallows; therefore they should be especially monitored during drier years to reduce fire spread.

Adult plantations seem to be particularly effective at reducing landscape flammability, especially if they are implemented in irregular fragments in already cleared lands. The viability of doing so in the study area seems to be high, given that the cultivation of oil palm following elongated shapes along access roads is a common practice among smallholders in the region (Gutiérrez-Vélez et al. 2011, Gutiérrez-Vélez and DeFries 2013). However, oil palm plantations also tend to become clustered in the landscape over time due to the necessity of locating them near processing facilities. This aggregation can undermine the effectiveness of plantations in reducing fire spread. Promoting exclusion zones between oil palm crops could reduce landscape flammability, but their implementation should consider economic feasibility among other factors.

In contrast to smallholders, most large-scale oil palm plantations are expanding into forests in the study area following more regular patterns (Gutiérrez-Vélez et al. 2011). Therefore, they are probably not as useful to reduce fire in the study area. In order for oil palm plantations to be effective at reducing fire occurrence and spread, they should be established in already cleared lands, especially if they replace highly flammable land covers such as pastures, as opposed to fire-resistant land covers such as old-growth forests. The success of oil palm plantations in reducing fire would depend on the implementation of measures to protect cultivations during the initial stages of development, because young plantations were positively correlated with fire occurrence and spread. Weed control in young oil palm plantations might also reduce fire risk, but its economic feasibility and the potential impacts on soil erosion should be evaluated. Finally, our study excluded degraded adult oil palm plantations. Thus, future research and landscape planning should consider the extent to which the presence of degraded adult plantations in a postproduction phase could increase fire risk.

\section{CONCLuSIONS}

This work contributes to the understanding of the extent to which land covers representing different stages of vegetation development and their interaction with drought severity influence fire occurrence and spread. We found that the area and configuration of different land covers can have a significant influence on fire occurrence and spread, but that the relationship is highly mediated by land cover type, the stage of development of vegetation, and drought severity.

Specifically, our work contributes to the understanding of the relationship between land cover changes and fire in tropical landscapes by showing that (1) there is a threshold after which the relationship between land 
covers representing different stages of development and fire changes from promoting to inhibiting burnings; (2) this threshold is strongly mediated by drought severity because drought severity increased the likelihood of fire as the area of land covers representing more developed stages of regrowth increased; (3) the establishment of perennial cultivations is not a precondition for reducing fire activity, but these cultivations have to develop enough to inhibit fire; and (4) after certain age, the relationship between perennial cultivations and fire occurrence is not significantly affected by drought conditions, in contrast to the area of secondary forests, which increases fire risk during dry years.

We also found that overall, irregular and scattered land cover patches correlated negatively with fire spread, but irregular patches of fallow and secondary forests increased fire spread during dry years. Adult oil palm was the only land cover for which irregularity consistently reduced fire spread, even during severely dry years.

In general, the promotion of large areas of secondary forests and adult oil palm plantations in cleared lands seems to be effective in reducing fire occurrence and spread, but adult oil palm plantations seem to be more effective at reducing fire occurrence and spread than is secondary vegetation, especially during dry years. These land covers can be effective in reducing fire only if they are expanded outside of forests. Interspersed and elongated shapes would further increase the effectiveness of adult plantations in reducing fire spread. Because young plantations are susceptible to fire, protection during the initial stages of development would be needed to develop an effective firebreak from adult plantations. Secondary forests would require special monitoring during severe droughts because they are susceptible to fire during those years. Ultimately, the feasibility of these strategies should consider and adapt to the variety of land tenure systems that exist across cleared lands in the Amazon, because some areas might require their own sets of fire management rules.

Cleared lands cover vast areas in the Amazon. These areas constitute a challenge, but also an opportunity to overcome the increasing incidence of fires and other environmental threats. The results of this work show that land cover management in cleared lands could potentially serve to reduce fire risk. Simultaneously, these land cover management strategies could provide food and ecosystem services such as water regulation, habitat improvement, and carbon sequestration. The success of such strategies will depend on developing incentives to promote and manage forest regrowth, expanding perennial crops such as oil palm plantations in cleared lands, and implementing early warning and other fire prevention and monitoring systems.

\section{ACKNOWLEDGMENTS}

This work was financed by the U.S. National Science Foundation (NSF) grant number 0909475 and the United States Agency for International Development (USAID) grant number EEM-G-00-04-00010-00. We thank Louis Verchot and Tien Ming Lee for their valuable feedback. We are also grateful to Walter Rios Perez, Isaac Perez, Medardo Miranda Ruiz, and other field assistants for their dedication in collecting the field data. Finally, we thank the two anonymous referees for their helpful reviews.

\section{Literature Cited}

Alencar, A., G. P. Asner, D. Knapp, and D. Zarin. 2011. Temporal variability of forest fires in eastern Amazonia. Ecological Applications 21:2397-2412.

Alencar, A., D. Nepstad, and M. C. V. Diaz. 2006. Forest understory fire in the Brazilian Amazon in ENSO and nonENSO years: area burned and committed carbon emissions. Earth Interactions 10:1-17.

Alencar, A. A. C., L. A. Solórzano, and D. C. Nepstad. 2004. Modeling forest understory fires in an Eastern Amazonian Landscape. Ecological Applications 14(Supplement):139149.

Aragão, L. E. O. C., Y. Malhi, N. Barbier, A. Lima, Y. Shimabukuro, L. Anderson, and S. Saatchi. 2008. Interactions between rainfall, deforestation and fires during recent years in the Brazilian Amazonia. Philosophical Transactions of the Royal Society B 363:1779-1785.

Aragão, L. E. O. C., and Y. E. Shimabukuro. 2010. The incidence of fire in Amazonian forests with implications for REDD. Science 328:1275-1278.

Barbaran-Garcia, J. 2000. Cuantificacion de biomasa y carbono en los principales sistemas de uso de suelo en Campo Verde. Universidad Nacional de Ucayali, Pucallpa, Peru.

Barlow, J., et al. 2012. The critical importance of considering fire in REDD+ programs. Biological Conservation 154:1-8.

Besag, J., J. York, and A. Mollie. 1991. Bayesian image restoration with two applications in spatial statistics. Annals of the Institute of Statistical Mathematics 43:1-59.

Blangiardo, M., M. Cameletti, G. Baio, and H. v. Rue. 2013. Spatial and spatio-temporal models with R-INLA. Spatial and Spatio-temporal Epidemiology 4:33-49.

Breiman, L. 2001. Random forests. Machine Learning 45:5-32.

Brown, F., W. Schroeder, A. Setzer, M. de los Rios Maldonado, N. Pantoja, A. Duarte, and J. Marengo. 2006. Monitoring fires in southwestern Amazonia rain forests. GEOS, Transactions, American Geophysical Union 87:253264.

Bruinsma, B. 2009. Producción de biodiesel de palma aceitera y jatropha en la Amazona del Perú y el impacto para la sostenibilidad: Un Análisis Sostenible del Ciclo de Vida. Thesis. Open Universiteit Nederland, Heerland, The Netherlands.

Cameletti, M., F. Lindgren, D. Simpson, and H. v. Rue. 2013. Spatio-temporal modeling of particulate matter concentration through the SPDE approach. AStA Advances in Statistical Analysis 97:109-131.

Carlson, K. M., L. M. Curran, D. Ratnasari, A. M. Pittman, B. S. Soares-Filho, G. P. Asner, S. N. Trigg, D. A. Gaveau, D. Lawrence, and H. O. Rodrigues. 2012. Committed carbon emissions, deforestation, and community land conversion from oil palm plantation expansion in West Kalimantan, Indonesia. Proceedings of the National Academy of Sciences USA 109:7559-7564.

Cochrane, M. A., and C. P. Barber. 2009. Climate change, human land use and future fires in the Amazon. Global Change Biology 15:601-612.

Cressman, G. P. 1959. An operational objective analysis system. Monthly Weather Review 87:367-374.

Díaz-Delgado, R., F. Lloret, and X. Pons. 2004. Spatial patterns of fire occurrence in Catalonia, NE, Spain. Landscape Ecology 19:731-745.

Dlamini, W. M. 2010. A Bayesian belief network analysis of factors influencing wildfire occurrence in Swaziland. Environmental Modelling and Software 25:199-208. 
European Commission. 2012. Global VGT burnt area product 2000-2007 (L3JRC). http://bioval.jrc.ec.europa.eu/products/ burnt_areas_L3JRC/download_13jrc.php

Fernandes, K., et al. 2011. North Tropical Atlantic influence on western Amazon fire season variability. Geophysical Research Letters 38:L12701.

Friday, K. S., M. E. Drilling, and D. P. Garrity. 1999. Imperata grassland rehabilitation using agroforestry and assisted natural regeneration. International Centre for Research in Agroforestry (ICRAF), Southeast Asian Regional Research Programme, Bogor, Indonesia.

Fujisaka, S., G. Escobar, and E. J. Veneklaas. 2000. Weedy fields and forests: interactions between land use and the composition of plant communities in the Peruvian Amazon. Agriculture, Ecosystems and Environment 78:175-186.

Fujisaka, S., and D. White. 1998. Pasture or permanent crops after slash-and-burn cultivation? Land-use choice in three Amazon colonies. Agroforestry Systems 42:45-59.

Gelman, A., and J. Hill. 2007. Data analysis using regression and multilevel/hierarchical models. Cambridge University Press, New York, New York, USA.

Gerritsma, W., and F. X. Soebagyo. 1999. An analysis of the growth of leaf area of oil palms in Indonesia. Experimental Agriculture 35:293-308.

Giglio, L., T. Loboda, D. P. Roy, B. Quayle, and C. O. Justice. 2009. An active-fire based burned area mapping algorithm for the MODIS sensor. Remote Sensing of Environment 113:408-420.

Gneiting, T., and A. E. Raftery. 2007. Strictly proper scoring rules, prediction, and estimation. Journal of the American Statistical Association 102:359-378.

Gobierno Regional de Ucayali. 2006. Evaluación de impactos ambientales de quema e incendios forestales en la provincia de Coronel Portillo. Gobierno Regional de Ucayali, Pucallpa, Peru.

Gutiérrez-Vélez, V. H., and R. DeFries. 2013. Annual multiresolution detection of land cover conversion to oil palm in the Peruvian Amazon. Remote Sensing of Environment 129:154-167.

Gutiérrez-Vélez, V. H., R. DeFries, M. Pinedo-Vasquez, M. Uriarte, C. Padoch, W. Baethgen, K. Fernandes, and Y. Lim. 2011. High-yield oil palm expansion spares land at the expense of forests in the Peruvian Amazon. Environmental Research Letters 6:044029.

Hansen, M., R. Dubayah, and R. DeFries. 1996. Classification trees: an alternative to traditional land cover classifiers. International Journal of Remote Sensing 17:1075-1081.

Hawbaker, T. J., V. C. Radeloff, S. I. Stewart, R. B. Hammer, N. S. Keuler, and M. K. Clayton. 2013. Human and biophysical influences on fire occurrence in the United States. Ecological Applications 23:565-582.

Lavorel, S., M. Flannigan, E. Lambin, and M. Scholes. 2007. Vulnerability of land systems to fire: Interactions among humans, climate, the atmosphere, and ecosystems. Mitigation and Adaptation Strategies for Global Change 12:33-53.

Le Page, Y., G. R. van der Werf, D. C. Morton, and J. M. C. Pereira. 2010. Modeling fire-driven deforestation potential in Amazonia under current and projected climate conditions. Journal of Geophysical Research 115:G03012.

Liaw, A., and M. Wiener. 2002. Classification and Regression by randomForest. R News 2:18-22.

Lima, A., T. S. F. Silva, L. E. O. C. de Aragão, R. M. de Feitas, M. Adami, A. R. Formaggio, and Y. E. Shimabukuro. 2012. Land use and land cover changes determine the spatial relationship between fire and deforestation in the Brazilian Amazon. Applied Geography 34:239-246.

Lojka, B., P. H. Cepkova, L. Navratilova, P. Van Damme, J. Banout, Z. Polesny, and D. Preininger. 2011. Methods for short-term control of Imperata grass in Peruvian Amazon. Journal of Agriculture and Rural Development in the Tropics and Subtropics (JARTS) 112:37-43.
LP-DAAC (NASA Land Processes Distributed Active Archive Center). 2001. MODIS vegetation indices MOD13Q1. Sioux Falls, South Dakota, USA. USGS/Earth Resources Observation and Science Center (EROS). http://reverb.echo.nasa. gov

Martino, S., and H. Rue. 2010. Implementing approximate Bayesian inference using integrated nested Laplace approximation: A manual for the inla program. Department of Mathematical Sciences, NTNU (Norwegian University of Science and Technology), Trondheim, Norway.

McGarigal, K., and B. Marks. 1995. FRAGSTATS: spatial pattern analysis program for quantifying landscape structure. General Technical Report PNW-GTR-351, U.S. Department of Agriculture, Forest Service, Pacific Northwest Research Station, Portland, Oregon, USA.

McKee, T. B., N. J. Doesken, and J. Kleist. 1993. The relationship of drought frequency and duration to time scales. Pages 179-183 in 84th Conference on Applied Climatology. American Meteorological Society, Boston, Massachusetts, USA.

Mohler, R. L., and D. G. Goodin. 2012. Identifying a suitable combination of classification technique and bandwidth(s) for burned area mapping in tallgrass prairie with MODIS imagery. International Journal of Applied Earth Observation and Geoinformation 14:103-111.

Moreira, F., F. Catry, F. Rego, and F. Bacao. 2010. Sizedependent pattern of wildfire ignitions in Portugal: when do ignitions turn into big fires? Landscape Ecology 25:14051417.

Moreira, F., et al. 2011. Landscape-wildfire interactions in southern Europe: implications for landscape management. Journal of Environmental Management 92:2389-2402.

Morton, D. C., R. S. DeFries, J. Nagol, C. M. Souza, Jr., E. S. Kasischke, G. C. Hurtt, and R. Dubayah. 2011. Mapping canopy damage from understory fires in Amazon forests using annual time series of Landsat and MODIS data. Remote Sensing of Environment 115:1706-1720.

Morton, D. C., R. S. DeFries, J. T. Randerson, L. Giglio, W. Schroeder, and G. R. Van Der Werf. 2008. Agricultural intensification increases deforestation fire activity in Amazonia. Global Change Biology 14:2262-2275.

Nepstad, D., G. Carvalho, A. Cristina Barros, A. Alencar, J. P. Capobianco, J. Bishop, P. Moutinho, P. Lefebvre, U. Lopes Silva, and E. Prins. 2001. Road paving, fire regime feedbacks, and the future of Amazon forests. Forest Ecology and Management 154:395-407.

Oliveira, P. J. C., G. P. Asner, D. E. Knapp, A. Almeyda, R. Galvan-Gildemeister, S. Keene, R. F. Raybin, and R. C. Smith. 2007. Land-use allocation protects the Peruvian Amazon. Science 317:1233-1236.

Padoch, C., E. Brondizio, S. Costa, M. Pinedo-Vasquez, R. R. Sears, and A. Siqueira. 2008. Urban forest and rural cities: multi-sited households, consumption patterns, and forest resources in Amazonia. Ecology and Society 13(2):2.

Pinedo-Vasquez, M., J. Barletti Pasqualle, D. del Castillo Torres, and K. Coffey. 2002. A tradition of change: the dynamic relationship between biodiversity and society in sector Muyuy, Peru. Environmental Science and Policy 5:4353.

R Development Core Team. 2013. R version 2.15.2. R: A language and environment for statistical computing. R Foundation for Statistical Computing, Vienna, Austria. http://www.r-project.org/

Roy, D. P., L. Boschetti, C. O. Justice, and J. Ju. 2008. The collection 5 MODIS burned area product - Global evaluation by comparison with the MODIS active fire product. Remote Sensing of Environment 112:3690-3707.

Rue, H., S. Martino, and N. Chopin. 2009. Approximate Bayesian inference for latent Gaussian models by using integrated nested Laplace approximations. Journal of the Royal Statistical Society B 71:319-392. 
Ruiz-Mirazo, J., J. Martínez-Fernández, and C. Vega-García 2012. Pastoral wildfires in the Mediterranean: understanding their linkages to land cover patterns in managed landscapes. Journal of Environmental Management 98:43-50.

Shlisky, A., A. A. C. Alencar, M. M. Nolasco, and L. M. Curran. 2009. Overview: Global fire regime conditions, threats, and opportunities for fire management in the tropics. Pages 65-83 in M. Cochrane, editor. Tropical fire ecology: climate change, land use, and ecosystem dynamics. Springer, New York, New York, USA.

Sierra, C. A., et al. 2007. Total carbon stocks in a tropical forest landscape of the Porce region, Colombia. Forest Ecology and Management 243:299-309.

Siljander, M. 2009. Predictive fire occurrence modelling to improve burned area estimation at a regional scale: a case study in East Caprivi, Namibia. International Journal of Applied Earth Observation and Geoinformation 11:380-393.

Silvestrini, R. A., B. S. Soares-Filho, D. Nepstad, M. Coe, H. Rodrigues, and R. Assunçao. 2011. Simulating fire regimes in the Amazon in response to climate change and deforestation. Ecological Applications 21:1573-1590.

Sorrensen, C. 2004. Contributions of fire use study to land use/ cover change frameworks: understanding landscape change in agricultural frontiers. Human Ecology 32:395-420.

Sorrensen, C. 2009. Potential hazards of land policy: Conservation, rural development and fire use in the Brazilian Amazon. Land Use Policy 26:782-791.

Sorrensen, C. L. 2000. Linking smallholder land use and fire activity: examining biomass burning in the Brazilian Lower Amazon. Forest Ecology and Management 128:11-25.
Spiegelhalter, D. J., N. G. Best, B. P. Carlin, and A. van der Linde. 2002. Bayesian measures of model complexity and fit. Journal of the Royal Statistical Society B 64:583-639.

Spracklen, D. V., S. R. Arnold, and C. M. Taylor. 2012. Observations of increased tropical rainfall preceded by air passage over forests. Nature 489:282-285.

Uhl, C., and J. B. Kauffman. 1990. Deforestation, fire susceptibility, and potential tree responses to fire in the eastern Amazon. Ecology 71:437-449.

Uriarte, M., M. Pinedo-Vasquez, R. S. DeFries, K. Fernandes, V. Gutiérrez-Vélez, W. E. Baethgen, and C. Padoch. 2012. Depopulation of rural landscapes exacerbates fire activity in the western Amazon. Proceedings of the National Academy of Sciences USA 109:21546-21550.

USGS (U.S. Geological Survey Department of the Interior). 2011. Global visualization viewer. USGS/Earth Resources and Science Center (EROS), Sioux Falls, South Dakota, USA. http://glovis.usgs.gov/

Vasconcelos, S. S. d., P. M. Fearnside, P. M. L. d. A. Graça, E. M. Nogueira, L. C. d. Oliveira, and E. O. Figueiredo. 2013. Forest fires in southwestern Brazilian Amazonia: Estimates of area and potential carbon emissions. Forest Ecology and Management 291:199-208.

Vega-García, C., and E. Chuvieco. 2006. Applying local measures of spatial heterogeneity to Landsat-TM images for predicting wildfire occurrence in Mediterranean landscapes. Landscape Ecology 21:595-605.

Viedma, O., D. Angeler, and J. Moreno. 2009. Landscape structural features control fire size in a Mediterranean forested area of central Spain. International Journal of Wildland Fire 18:575-583.

\section{Supplemental Material}

\section{Appendix A}

Remote sensing methods for burn scar mapping (Ecological Archives A024-079-A1).

\section{Appendix B}

Tables with burn scar and fuel sampling intensity and additional modeling results (Ecological Archives A024-079-A2).

\section{Appendix C}

Figures illustrating methods and results for burn scar mapping, fuel sampling and statistical analysis (Ecological Archives A024-079-A3). 